\title{
The new heart transplant allocation system: Early observations and mechanical circulatory support considerations
}

\author{
Jerry D. Estep, MD, ${ }^{\mathrm{a}, \mathrm{b}}$ Edward Soltesz, MD, MPH, ${ }^{\mathrm{b}, \mathrm{c}}$ and Rebecca Cogswell, $\mathrm{MD}^{\mathrm{d}}$
}

Feature Editor Note-In October of 2018, a new 6-tiered system for allocation of donor organs for heart transplantation was initiated in the United States through the United Network for Organ Sharing. The new heart transplant allocation system was devised to address important limitations in the former 3-tier heart allocation system that included discrepancies in the assignment of listing priority relative to patient risk characteristics and limitations in the allocation of donor organs based upon the use of the local organ procurement organization as a unit for allocation of organs. The major goal of the new allocation system was to reduce mortality on the waitlist by improving the stratification of high-risk groups and provide improved and more equitable geographic access to donor organs. Now, nearly 2 years into the new allocation scheme, considerable data from the Organ Procurement Transplant Network have accrued that have provided important insight into patient outcomes and changes in clinical practice that have occurred as a result of the changes in the heart transplantation allocation system. Although the overall assessment is that the new heart transplant allocation system has brought important positive changes to the allocation of donor organs and heart transplant outcomes, these changes have occurred amidst some unfavorable or unwanted occurrences, such as an increase in travel distances to donor hospitals and increase in the donor allograft ischemic time. Further, the change in the heart transplant allocation system has had significant influences on the field of mechanical circulatory support and bridge to transplant strategies. In this issue of the Journal, Estep and colleagues provide an

From the Departments of ${ }^{\mathrm{a}}$ Cardiovascular Medicine and ${ }^{\mathrm{c}}$ Thoracic and Cardiovascular Surgery, Cleveland Clinic Sydell and Arnold Miller Family Heart, Vascular \& Thoracic Institute, Cleveland, Ohio; ${ }^{b}$ Kaufman Center for Heart Failure and Recovery, Cleveland Clinic, Cleveland, Ohio; and ${ }^{\mathrm{d}}$ Division of Cardiology, Department of Medicine, University of Minnesota, Minneapolis, Minn.

Received for publication March 31, 2020; revisions received July 30, 2020; accepted for publication Aug 8, 2020; available ahead of print Sept 16, 2020.

Address for reprints: Jerry D. Estep, MD, 9500 Euclid Ave, J3-4, Cleveland, OH 44195 (E-mail: estepj@ccf.org).

J Thorac Cardiovasc Surg 2020;161:1839-46

$0022-5223 / \$ 36.00$

Copyright (c) 2020 by The American Association for Thoracic Surgery

https://doi.org/10.1016/j.jtcvs.2020.08.113

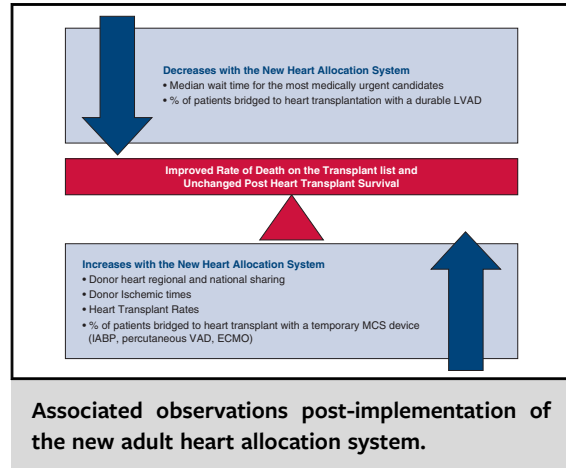

CENTRAL MESSAGE

The new adult heart allocation system has resulted in broader sharing, greater use of temporary MCS devices, reduced median wait time along with improved wait list, and unchanged posttransplant survival.

This Invited Expert Opinion provides a perspec tive on the following paper: J Heart Lung Trans plant. 2020; 39:1-4. https://doi.org/10.1016/j.healun. 2019.11.002.

See Commentaries on pages $1847,1848,1849$, and 1851.

in-depth overview of the impact the new heart allocation system has had on heart transplant outcomes in the United States and provide a thoughtful perspective of how the new allocation system has changed clinical practice.

\section{Francis D. Pagani, MD, PhD}

Implementation of significant changes to the United States adult heart allocation system occurred October 18, 2018. A goal behind these changes was to decrease mortality rates for recipients on the waiting list with better stratification of the most medically urgent heart transplant candidates while also addressing geographic disparities in access to donors. ${ }^{1}$ Concerned that the former 3-tier allocation system did not 
prioritize enough urgency for some patients, the United Network for Oran Sharing (UNOS) implemented a 6-tiered system with more specific guidelines for each tier (Table 1). Although heart allocation policy has traditionally been based on wait-list mortality rather than post-transplant outcomes, the desire to balance the needs of critically ill patients with long-term post-transplant outcomes remains a priority, given a donor heart remains a limited resource. The purpose of this review is to highlight the impact of the new donor heart allocation system in the United States, provide mechanical circulatory support (MCS) considerations for the most urgent tiered statuses, and define programmatic considerations in light of the new allocation system.

\section{EARLY OUTCOME OBSERVATIONS WITH THE NEW 2018 DONOR HEART ALLOCATION SYSTEM \\ There have been a few early looks at the impact of the modifications to adult heart allocation. The earliest report by Cogswell and colleagues ${ }^{2}$ demonstrated worse post-transplant 180-day survival estimates with the new system compared with the old system. In contrast, based}

on the Organ Procurement and Transplantation Network (OPTN) 1-year follow up of the Heart Allocation Proposal, there was no reported difference in graft and patient survival comparing the old and new allocation system. ${ }^{3}$ Cogswell and colleagues ${ }^{2}$ compared outcomes of those listed and transplanted in the 3 years before the UNOS allocation change (previous system, $\mathrm{N}=6001$ ) with those listed and transplanted under the new system (after October 18, 2018-March 31, 2019, $\mathrm{N}=539$ ). Comparing patients listed and transplanted in the new system versus old system, patients in the new system (1) were more likely to be on temporary MCS $(41 \%$ vs $10 \% ; P<.0001)$, (2) had worse hemodynamics, (3) were less likely to be transplanted with a durable left ventricular assist device (LVAD) support $(23 \%$ vs $42 \%)$, and (4) had longer ischemic times $(3.4 \pm 0.96$ vs $3.0 \pm 1.0 ; P<.0001) .180$-day survival on the waitlist in new system was better, $96.1 \%$ (95\% confidence interval $[\mathrm{CI}], 94.5 \%-95.5 \%$ ) compared with $95 \%$ in the old system $(95 \%$ CI, $94.2 \%-97.3 \%, \log$ rank $P=.08$ ), and the 180-day post-transplant survival estimates were worse, $77.9 \%$ versus $93.4 \%(\log$-rank $P<.0001){ }^{2}$

TABLE 1. Comparison of old and new adult heart allocation systems

\begin{tabular}{|c|c|c|}
\hline Old adult heart allocation system & New adult heart allocation system & Criteria \\
\hline Status 1A & $\begin{array}{l}\text { Status } 1 \\
\text { Status } 2 \\
\text { Status } 3\end{array}$ & $\begin{array}{l}\text { ECMO } \\
\text { Nondischargeable BiVAD } \\
\text { MCS with VT } \\
\text { IABP } \\
\text { Percutaneous VADs } \\
\text { Surgical nondischargeable LVAD } \\
\text { TAH } \\
\text { MCS with device failure } \\
\text { VT/VF } \\
\text { LVAD } \times 30 \mathrm{~d} \text { (discretionary use) } \\
\text { High dose or }>1 \text { inotrope } \\
\text { Status } 1 \text { and } 2 \text { after } 14 \mathrm{~d} \\
\text { MCS with other complication }\end{array}$ \\
\hline Status 2 & Status 4 & $\begin{array}{l}\text { Stable LVAD } \\
\text { Inotropes without monitoring } \\
\text { Retransplant } \\
\text { Diagnosis } \\
\text { Complex CHD } \\
\text { HCM } \\
\text { RCM } \\
\text { ICM with intractable angina } \\
\text { Amyloidosis }\end{array}$ \\
\hline & Status 5 & Combined organs \\
\hline & Status 6 & All others \\
\hline
\end{tabular}

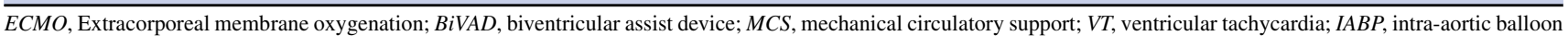
pump; $V A D$, ventricular assist device; $L V A D$, left ventricular assist device; $T A H$, total artificial heart; $V F$, ventricular fibrillation; $C H D$, congenital heart disease; $H C M$, hypertrophic cardiomyopathy; $R C M$, restrictive cardiomyopathy; ICM, ischemic cardiomyopathy. 


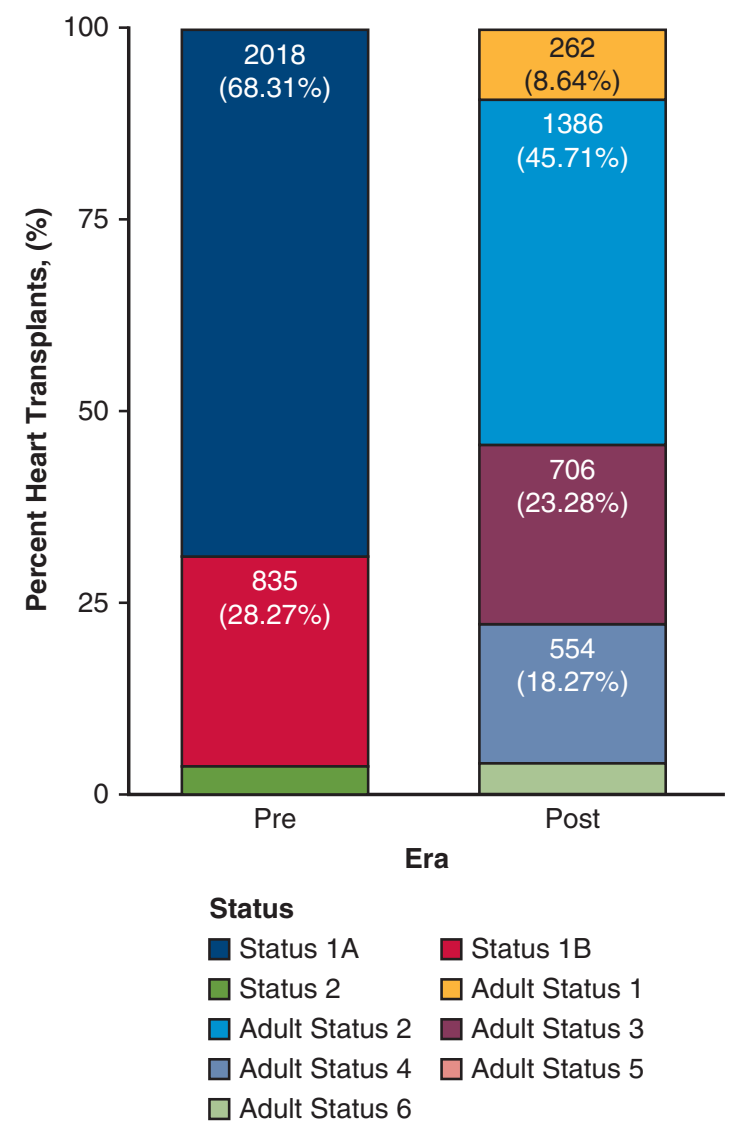

FIGURE 1. Proportion of adult heart transplants by medical urgency status and era. The proportion of adult heart transplants performed both preand post-implementation by medical urgency status. Status 1A candidates received around two-thirds of all transplants pre-implementation, but no single status represented such a large fraction of transplants postimplementation. Adult Status 2 candidates received the most transplants, followed by Adult Status 3, Adult Status 4, and Adult Status 1. Postimplementation Adult Status 6 represented only $3.63 \%$ of transplants, whereas there were only $14(0.46 \%)$ transplants to Adult Status 5 patients in the first year after the new adult heart allocation policy went into effect. Adopted from the OPTN Thoracic Transplantation Committee. ${ }^{3}$ Statuses representing less than $5 \%$ of the total are not labeled on the plot.

It is important to highlight the limitations of this first early investigation. There was a small sample size, with only 539 patients in the new system with only 32 deaths and 3 retransplants. Although outcomes were available up to June 6, 2019, for new system recipients, the actual observed follow-up in this group was very short. Moreover, whether these early trends would persist over a longer period of observation remained uncertain. Concern that this analysis was performed "too early," that is, before the recovery of complete recipient follow-up information, and resulted in biased results has been reported. ${ }^{4,5}$

Early monitoring of the new heart transplant allocation system has also provided OPTN with data made available February 21, 2020. ${ }^{3}$ In the new system, Adult Status 2 candidates received the most transplants $(45.7 \%)$, followed by Adult Status $3(23.3 \%)$, Adult Status $4(18.3 \%)$, and Adult Status 1 (8.6\%) (Figure 1). Based on OPTN data, the median distance traveled in the new system increased significantly $(P<.001)$, from a preimplementation median of 83 nautical miles to a post-implementation median of 216 nautical miles. ${ }^{3}$ In line with what was reported by Cogswell and colleagues, ${ }^{2}$ total ischemic times were significantly longer in the new system (mean of 3.4 hours from 3 hours, $P<.001$ ) (Figure 2). Most importantly, different from the early report by Cogswell and colleagues, ${ }^{2}$ the OPTN outcome data are on based on 1658 adult heart recipients transplanted between October 18, 2017, and May 17, 2018 (old system) and 1689 adult heart recipients transplanted between October 18, 2018, and May 17, 2019 (new system), which equates to a greater sample size and follow-up in the new system. There was no difference in graft and patient survival when comparing the old and implementation of the new allocation system (Figure 3). Although the Kaplan-Meier curves appear to be divergent at 6-month follow-up, patient survival was $93.53 \%$ compared with $92.81 \%$ in the new system $(P=.42)$. Unadjusted and adjusted hazard ratios with CIs were not reported. ${ }^{3}$ Continued follow-up monitoring and a larger sample size remain key to better understand the long-term implications of new allocation system.

Early monitoring suggests that revisions to the heart allocation system have resulted in broader sharing and hearts traveling greater distances to be transplanted. Changes to the adult heart allocation system have also substantially reduced the median time spent waiting before receiving a transplant, especially for the most medically urgent candidates. Importantly waiting list survival and post-transplant outcomes have remained constant. ${ }^{3}$

\section{URGENT HEART TRANSPLANT AND STATUS 1 CONSIDERATIONS \\ Venoarterial Extracorporeal Membrane Oxygenation (VA-ECMO)}

Based on early investigations with the new donor heart allocation system, VA-ECMO use as bride to heart transplantation is up $\sim 4$-fold compared with use in the old system. ${ }^{2,3}$ The median time to transplant for Status 1 based on the OPTN data is 4 days. ${ }^{3}$ Both early examinations of the new heart transplant allocation system lack robustness for substratifying outcomes within the hierarchal categories of Status 1. However, based on the OPTN data, it is reassuring to see a 6 -month patient survival $\sim 88 \%$ to $89 \%$ for those registered as Status 1 including a registration count of 160 with VA-ECMO use at the time of transplant (Figure 4). ${ }^{3}$

Several investigations have linked VA-ECMO use preheart transplant in the older heart allocation system with poor 1-year post transplant survival $\sim 51 \%$ to $71 \%$. $^{6-12}$ 


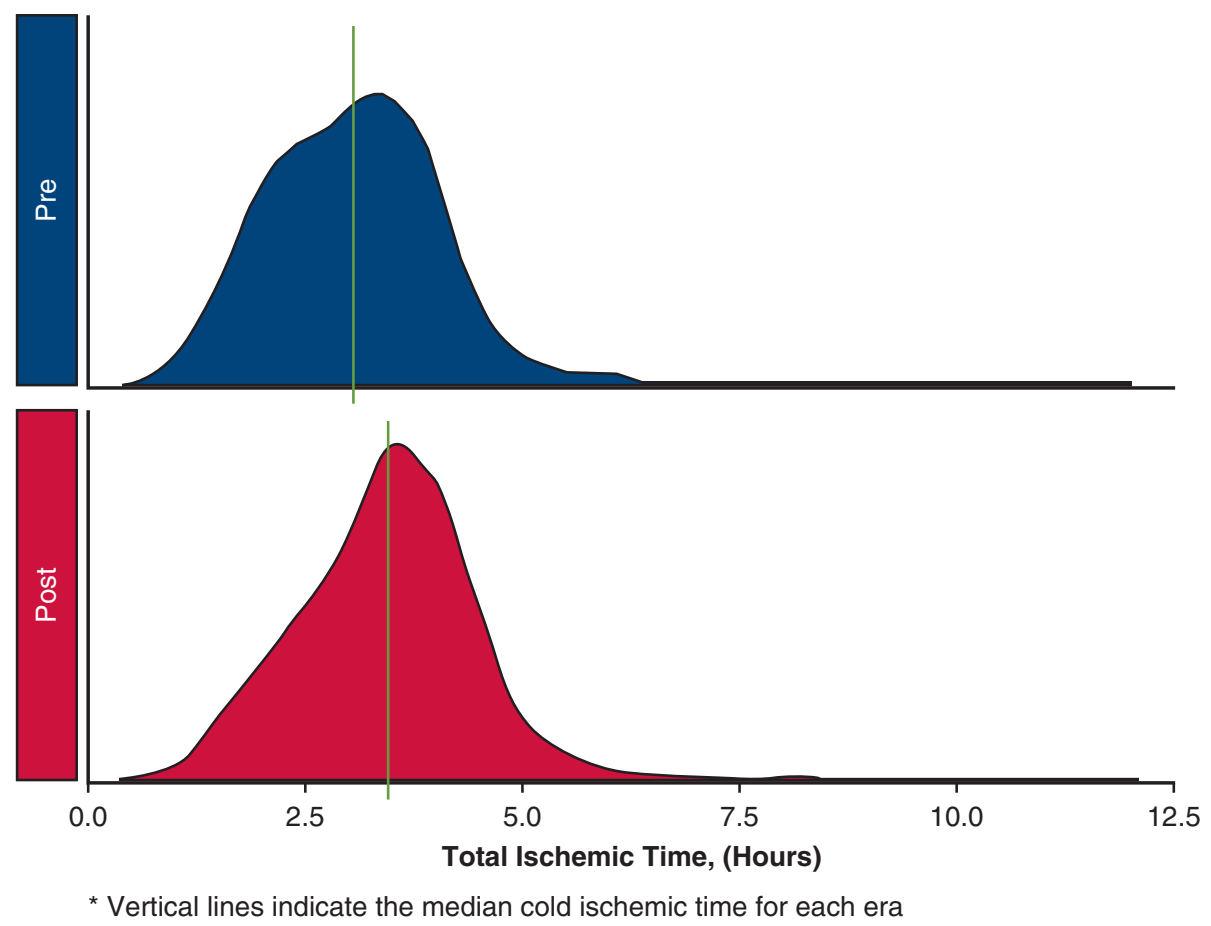

FIGURE 2. Total ischemic time at transplant by era. Distribution of total ischemic times at transplant both pre- and post-implementation, where total ischemic time is defined as the sum of cold ischemic time, warm ischemic time, and anastomotic time. Total ischemic times increased significantly $(P<.001)$ post-implementation to a mean of 3.4 hours from 3 hours. The maximum ischemic time reported during the pre-implementation era was the same as the maximum ischemic time reported during the post-implementation era: 12 hours. Adopted from the OPTN Thoracic Transplantation Committee. ${ }^{3}$

Most recently, Yin and colleagues ${ }^{6}$ used data from 2005 to 2016 from the International Society for Heart and Lung Transplantation Thoracic Transplant Registry to examine the clinical outcome after heart transplantation in patients supported by durable and temporary MCS. Of 322 patients bridged to transplant with temporary MCS not including intra-aortic balloon pump (IABP) use, 134 were with the use of VA-ECMO. ${ }^{6}$ Compared with the other MCS bridge strategies, bridging with VA-ECMO was associated with the worst post heart transplant survival (hazard ratio, 3.79; 95\% CI, 2.69-5.34, $P<.001$ ) (Figure 5). ${ }^{6}$ The French experience also demonstrated an increase in mortality transplanting patients supported by VA-ECMO. In 2004, the French introduced "high emergency 1" status that allowed patients supported by VA-ECMO or dependent on inotropes to be prioritized at the top of the waiting list. A significant increase in 1-year mortality was observed, which was attributed to patient acuity and greater post-transplant adverse. ${ }^{7}$ More recently, based on the French CRISTAL national registry more favorable outcomes were reported in patients listed on VA-ECMO; however, post-transplant survival remained inferior to patients without VA-ECMO. ${ }^{8}$

Others, albeit based on single-center retrospective studies, have reported better post-transplant survival after VA-ECMO use. ${ }^{13}$ This highlights the importance of institution-based practices that can be adopted to optimize outcome during and after VA-ECMO support. ${ }^{14}$ Strategies to optimize left ventricular unloading and mitigate complications like limb ischemia with preventive placement of antegrade distal perfusion cannulas may help curb adverse outcomes while on the waiting list and after heart transplantation. Individual programs must balance the benefits and risks of urgent transplant versus early transition to a durable mechanical support for those without signs of myocardial recovery and who have sufficient underlying right ventricular dysfunction.

\section{Surgically Placed Nondischargeable Biventricular Assist Devices (BiVADS)}

An alternative to VA-ECMO use to support patients with biventricular failure is with surgically implanted, nondischargeable biventricular devices. There are a paucity of data using this configuration in waitlisted patients. Yin and colleagues ${ }^{6}$ examined 75 nondischargeable, surgically implanted BIVADS as a bridge to heart transplant (BTT) with the use of CentriMag Bi-VADs (Abbott, Abbott Park, Ill). ${ }^{6}$ The Kaplan-Meier estimates for patient survival within 1 year of transplant among those supported by CentriMag Bi-VADs was $89.5 \%$, which was similar to the continuous-flow durable LVAD BTT group $(89.6 \%)$ and better than the other groups supported by the other short-term devices (IABP use not included) (Figure 5). Risks with CentriMag BiVADs use include bleeding, hemolysis, thromboembolism, and infection. 

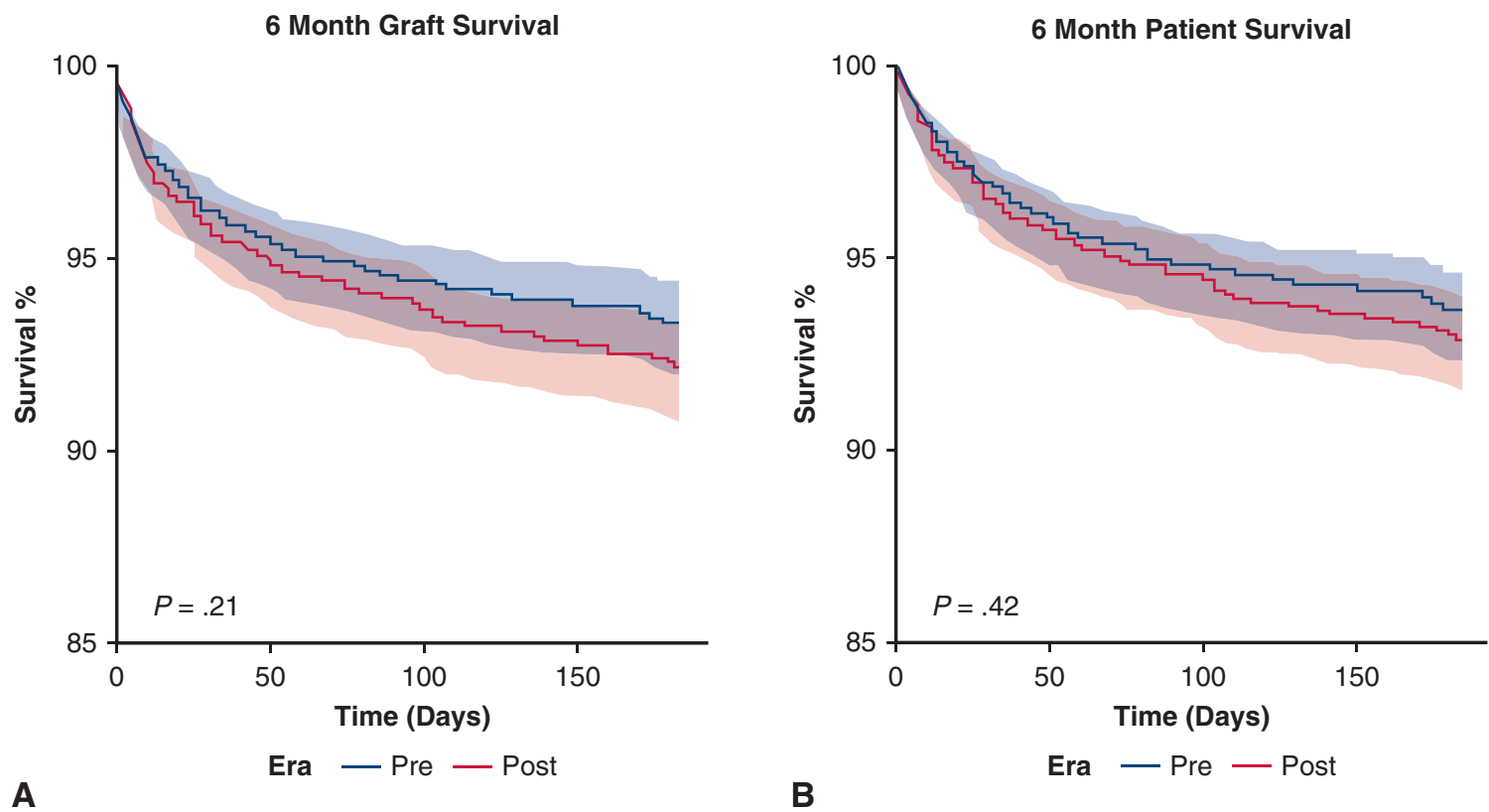

FIGURE 3. Six-month graft and patient survival for adult heart recipients pre- and post-implementation. A, Six-month graft survival in the pre-era was $93.3 \%$ compared with $92.14 \%$ in the post era. The difference is not statistically significant $(P=.21)$. B, Six-month patient survival in the pre-era was $93.53 \%$ compared with $92.81 \%$ in the post era. The difference is not statistically significant $(P=.42)$. Adopted from the OPTN Thoracic Transplantation Committee. ${ }^{3}$

\section{URGENT TRANSPLANT AND STATUS 2 CONSIDERATIONS \\ Intra-Aortic Balloon Pumps}

Prior to the roll out of the new heart transplant allocation system, IABP use was already increasing..$^{15}$ Using the National Inpatient Sample from 1998 to 2014, Ouyang and colleagues ${ }^{15}$ identified patients who received a heart transplant and classified them by pretransplant IABP, percutaneous ventricular assist devices (VADs), VA-ECMO, or no pretransplant temporary MCS. During the study period, the use of temporary MCS more than doubled. In this cohort, IABP accounted for $341(74.8 \%)$ of the patients with temporary MCS as a BTT, compared with $(28.5 \%)$ supported by VA-ECMO, and $4.6 \%$ supported by a percutaneous VADs. ${ }^{15}$ Based on the 1-year monitoring after implementation of the new heart transplant allocation system, IABP use at the time of heart transplant is up $\sim 3$ fold $(13.2 \%$ up to $38.2 \%$ ), including a registration count of 822 IABP use at the time of transplant.

Although the femoral artery is commonly used for access, the positive safety profile and feasibility of transthoracic IABPs that permit upright sitting and ambulation has been reported by several investigators. ${ }^{16,17}$ Transthoracic IABPs can be placed surgically by attaching a graft to the subclavian or axillary artery. Alternatively, Estep and colleagues ${ }^{17}$ published a percutaneous approach using a micropuncture guidewire roadmap technique that permits placement of a sheath into the axillary artery without needing a surgical cut down or graft conduit. ${ }^{18}$
Approximately $80 \%$ of 50 listed heart transplant patients had stabilization with percutaneous axillary IABP support and underwent heart or heart-multiorgan transplant. ${ }^{17}$ Most recently, Bhimaraj and colleagues ${ }^{19}$ reported on this extended, largest, single-center axillary IABP experience using percutaneously placed IABPs in the left axillary artery as a BTT. Among 120 patients who underwent heart or heart-multiorgan transplant, 1-year patient survival was $87 \%{ }^{19}$ Based on several case series including 163 BTT patients, 141 patients (86.5\%) were successfully transplanted with support that ranged from 3 to 152 days. The most frequent complications attributed to extended support were device malfunction or migration necessitating exchange or repositioning $(37.3 \%) .{ }^{16}$ Based on these observations, it is anticipated that the IABP will be the predominately used temporary MCS device used to support patients in the new allocation system and post-heart transplant survival is expected to remain at least constant if not better compared to other bridge strategies.

\section{Percutaneous Ventricular Assist Devices}

Based on the National Inpatient Sample, Ouyang and colleagues ${ }^{15}$ identified 21 of 456 patients who received a heart transplant with temporary MCS use specifically by a percutaneous LVAD including one of the Impella devices (Abiomed, Danvers, Mass) or the TandemHeart (Cardiac Assist Inc; LivaNova, London, United Kingdom). Based on this examination, before the implementation of the new allocations system, percutaneous VAD use a BTT was less than IABP and VA-ECMO use for this support intent but the 


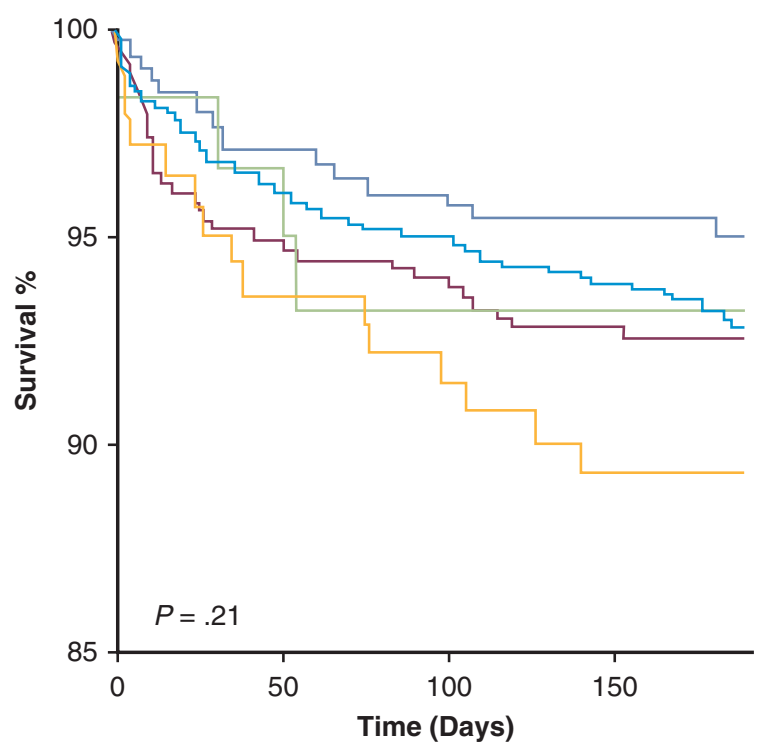

Status

- Adult Status 1 - Adult Status 2

- Adult Status 3 - Adult Status 4

- Adult Status 6

${ }^{*}$ Adult Status 5 is omitted because there were too few adult heart recipients to accurately estimate survival

FIGURE 4. Six-month patient survival by medical urgency status post-implementation. Adopted from the OPTN Thoracic Transplantation Committee. ${ }^{3}$

use of these types of devices was noted to be on the rise. ${ }^{15}$ Based on the OPTN data, the percutaneous VAD with the greatest increase use comparing device registrations at the time of transplant (old vs new system) is the Impella 5.0 (up from $2.18 \%$ to $6.78 \%$, representing an $\sim 3$-fold increase). Similar to Status 1 device considerations, early examinations of the outcome with the new heart transplant allocation system lack robustness for substratifying outcomes within the hierarchal categories of Status 2.

Based on the International Society for Heart and Lung Transplantation registry, BTT with a percutaneous VAD $(\mathrm{N}=75)$ was independently associated with greater risk of post-transplant mortality (hazard ratio, $1.83 ; 95 \% \mathrm{CI}$, $1.09-3.08, P=.02$ ) with survival at 1 year at $79.9 \%$. The only other device bridge group with poorer outcome was the VA-ECMO group. ${ }^{6}$ In contrast, based on a retrospective evaluation at 3 centers of patients with advanced HF who acutely decompensated and received the Impella 5.0 for bridge to decision, among 39 patients who survived to next therapy, 15 patients received a heart transplant. One-year post transplant survival was $87 \%$ for these select patients. Infection and bleeding requiring transfusion were the most common in-hospital complications, affecting $19 \%$ and $16 \%$ of patients supported by this device. ${ }^{20}$ As more time passes in the new US heart allocation era, more precise estimates of waitlist outcomes and post-transplant mortality will be able to be calculated in patients supported with specific percutaneous VADs.

\section{HEART TRANSPLANT AND STATUS 3 AND 4 CONSIDERATIONS \\ Durable LVADs}

Durable LVADs offer a long-term alternative to transplant. Stable patients with LVADs without complications are in Status 4, a lower tier in the new US allocation system. Patients supported by LVADs with life-threatening ventricular arrhythmias may be considered for Status 1 listing and those with device malfunction (currently much less common with the HM 3 device $^{21}$ ) may be considered for Status 2 listing. Similar to the old heart allocation system, discretionary 30-day use remains permissible now at Status 3 for stable patients on LVAD support.

Improvements in device designs and clinical improvements account for an improvement in outcomes, reaching a 2-year survival $\sim 82 \%$ that is comparable to heart transplant with the current continuous flow LVADs. ${ }^{21,22}$ Survival at 1 year was significantly greater for the centrifugal-flow with full magnetic levitation devices than for centrifugal flow with hybrid levitation devices $(87 \%$ vs $79 \%$, $P<.001){ }^{22}$ Based on early UNOS investigations and the most recent STS/INTERMACS report, the effect of the new US heart allocation system has manifested in dramatic change in the distribution of LVAD implant strategies over time. ${ }^{2,3,22}$ Before 2018 , approximately $25 \%$ of patients received a LVAD as BTT candidacy, $25 \%$ as BTT, and about half as destination therapy. However, since the introduction of the new heart allocation system, less than $10 \%$ of the implants were BTT and more than $70 \%$ were destination therapy in $2019 .^{22}$ This trend is anticipated to continue.

\section{Underlying Heart Disease}

The new heart transplantation allocation scheme includes types of heart disease as a lower tier with preference given to patients deemed to be at a survival disadvantage with underlying restrictive cardiomyopathy, hypertrophic cardiomyopathy, complex congenital heart disease, and amyloidosis. Less than $20 \%$ of transplanted patients in the new system were categorized as Status 4 (Figure 1). ${ }^{3}$ Based on early observations, 6-month patient survival in this status is encouraging at $\sim 95 \%$ (Figure 4 ). ${ }^{3}$ Also reassuring is the number of deaths per 100 patient years waiting by medical urgency for Status 4 (5 with a CI [4-6]) is less than Status 1, 2, and 3 with the number of deaths per 100 patient years waiting reported as 139, CI [69-248], 33, CI [20-49], and 7, CI [4-12,] respectively. ${ }^{3}$ Anticipating a greater sample size with increased follow-up, it will be important to define the percentage of patients listed and transplanted as Status 4, upgrade status changes frequency, waitlist mortality or delisting and post-transplant graft and patient survival. 


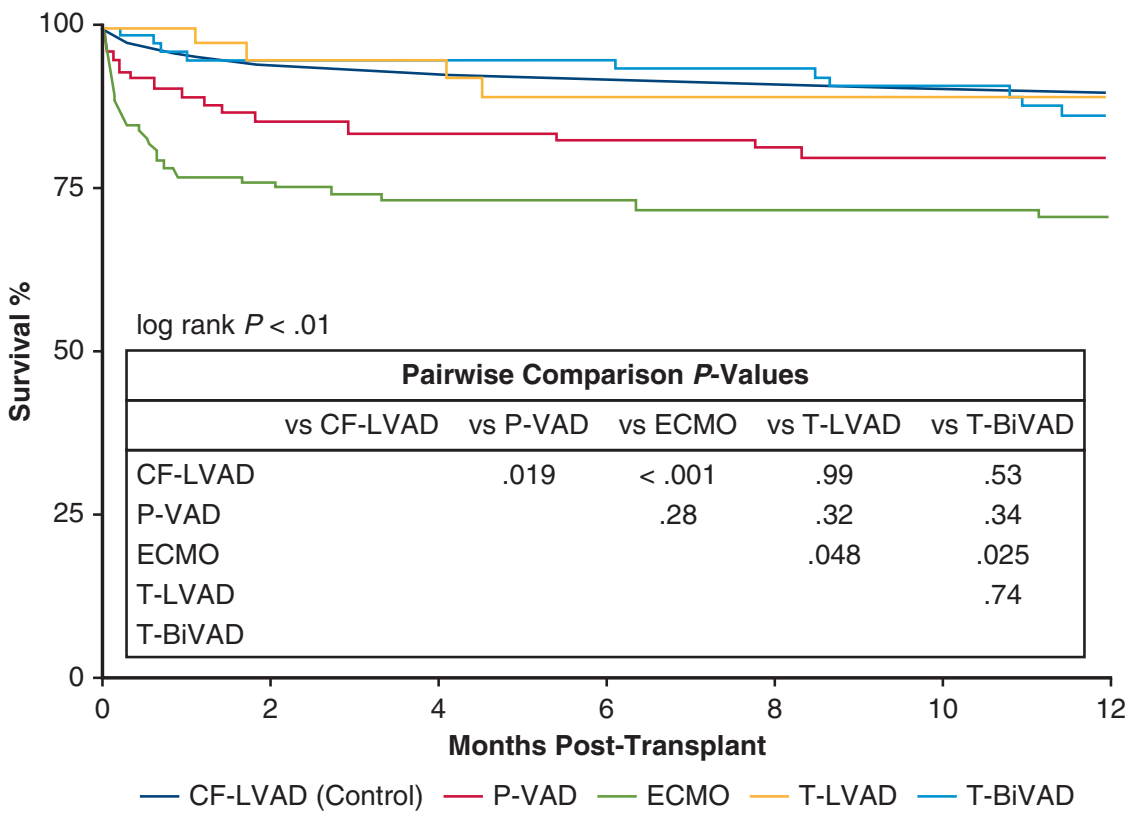

\begin{tabular}{|c|c|c|c|c|c|}
\hline \multicolumn{6}{|c|}{ Months Post-Transplant } \\
\hline \multicolumn{2}{|c|}{1 Month } & \multicolumn{2}{|c|}{6 Months } & \multicolumn{2}{|c|}{12 Months } \\
\hline $\begin{array}{l}\text { Number } \\
\text { at Risk }\end{array}$ & $\begin{array}{c}\text { Survival } \\
(95 \% \mathrm{Cl}) \%\end{array}$ & $\begin{array}{l}\text { Number } \\
\text { at Risk }\end{array}$ & $\begin{array}{c}\text { Survival } \\
(95 \% \mathrm{Cl}) \%\end{array}$ & $\begin{array}{l}\text { Number } \\
\text { at Risk }\end{array}$ & $\begin{array}{c}\text { Survival } \\
(95 \% \mathrm{Cl}) \%\end{array}$ \\
\hline 5902 & $95.5(95.0,96.0)$ & 5644 & $91.8(91.1,92.5)$ & 5314 & $89.6(88.8,90.3)$ \\
\hline 68 & $89.3(82.6,96.6)$ & 61 & $82.6(74.4,91.7)$ & 55 & $79.9(71.2,89.5)$ \\
\hline 99 & $76.0(69.0,83.6)$ & 94 & $72.8(65.6,80.8)$ & 86 & $71.2(63.9,79.4)$ \\
\hline 38 & $100.0(100.0,100.0)$ & 35 & $89.5(80.2,99.8)$ & 31 & $89.5(80.2,99.8)$ \\
\hline 72 & $94.7(89.7,100.0)$ & 69 & $94.7(89.7,100.0)$ & 60 & $86.2(78.6,94.5)$ \\
\hline
\end{tabular}

FIGURE 5. Kaplan-Meier estimates for patient survival within 1 year. Pairwise survival was compared with log-rank tests. $C F-L V A D$, Continuous-flow left ventricular assist devices; $P$-VAD, percutaneous ventricular support devices; $E C M O$, extracorporeal membrane oxygenation; T-LVAD, nondischargeable, surgically implanted left ventricular support systems; T-BiVAD, nondischargeable, surgically implanted biventricular support system; $C I$, confidence interval. Adopted with permission from Yin and colleagues. ${ }^{6}$

\section{Programmatic Considerations}

In the case that transplant candidates acutely decompensate and are in need of MCS, a transplant program will need to decide if a short-term device or a durable device should be implanted. Although outcomes have improved with LVADs, ${ }^{21,22}$ heart transplantation remains the gold standard for eligible patients based on a median survival of approximately 12.5 years. ${ }^{23}$ This is especially true for those patients with contraindications to LVAD therapy. Providers at advanced heart failure programs are now positioned to support patients with temporary MCS devices anticipating a relative short waiting time (median waiting time for Status 1 is 4 days and for Status 2 is 9 days). ${ }^{3}$ As more programs adopt this strategy, however, crowding at the top of the list may prolong wait times for patients who are Status 2 . In addition, wait times remain influenced by $\mathrm{ABO}$ blood type and recipient size. Under the UNOS guidelines, temporary MCS use is guided by the underlying hemodynamic support need. Consideration for device escalation should be based on worsening hemodynamics, recognizing partial left ventricular unloading can been seen with all devices and/or device combinations. Worsening hemodynamics combined with greater ischemic times could translate into worse post-heart transplant outcomes in the new allocation system. In addition, it will be important to monitor the costeffectiveness of heart transplant as programs adjust to the new allocation system and increased costs attributed to increased temporary MCS use and organ-acquisition fees related to increased travel distance are realized.

Regarding the impact of the new allocation system on center volume, the investigation by Cogswell and colleagues $^{2}$ was not powered to assess the effect of regional or center heterogeneity on outcomes. Based on the recent OPTN data, there were 124 transplant centers that performed at least 1 adult heart transplant in 1 of the 2 eras pre- and post-implementation of the new allocation system. Of those, 58 performed more adult heart transplants postimplementation than they did pre-implementation. There were 56 centers that performed fewer adult heart transplants after implementation than they did pre-implementation and, 
of these, 26 did more than $25 \%$ fewer transplants postimplementation than they did pre-implementation. ${ }^{3}$ While some transplant centers have seen a decrease in transplant volume, the difference may relate to waiting list composition rather than the change in allocation policy. To our knowledge, an examination of the impact on center volume and graft and patient survival outcome in the new allocation system has not been performed.

\section{CONCLUSIONS}

Early investigations of new heart transplant allocation system suggest that revisions have resulted in broader sharing, greater ischemic times, and greater use of temporary MCS devices including the IABP, Impella 5.0, and VA-ECMO. Changes to the adult heart allocation system have also substantially reduced the median time spent waiting before receiving a transplant, especially for the most medically urgent candidates including Status 1 and 2. In addition, in this new era, a significantly lower percentage of patients implanted with durable LVADs are being implanted as BTT strategy. Importantly, waiting list survival is improved and post-transplant outcomes are not statistically different in the most recent unadjusted OPTN analysis. Anticipating a greater number of patients on temporary MCS at the time of transplant in the new allocation system coupled with complete follow up, substratifying outcomes within the hierarchal categories of each status will be an important next step to guide future decision making.

\section{Conflict of Interest Statement}

Dr Estep reported consultant for Abbott, medical advisor for Medtronic, Inc, consultant for Getinge, and Scientific Advisor Consultant for NupulseCV, Inc. Dr Soltesz reported consultant for Abbott, consultant for Abiomed, consultant for Edwards, and consultant for AtriCure. Dr Cogswell reported medical advisor for Medtronic, Inc, and husband's employment at Abbott lab (speakers bureau).

The Journal policy requires editors and reviewers to disclose conflicts of interest and to decline handling or reviewing manuscripts for which they may have a conflict of interest. The editors and reviewers of this article have no conflicts of interest.

\section{References}

1. Stevenson LW, Kormos RL, Young JB, Kirklin JK, Hunt SA. Major advantages and critical challenge for the proposed United States heart allocation system. $J$ Heart Lung Transplant. 2016;35:547-9.

2. Cogswell R, John R, Estep JD, Duval S, Tedford RJ, Pagani FD, et al. An early investigation of outcomes with the new 2018 donor heart allocation system in the United States. J Heart Lung Transplant. 2020;39:1-4.

3. OPTN Thoracic Transplantation Committee. One-Year Monitoring of Heart Allocation Proposal to Modify the Heart Allocation System. Available at: https://optn.transplant.hrsa.gov/media/3701/data_report_thoracic_committee_ heart_subcommittee_20200227_rpt1_revised_508_compliant.pdf. Accessed March 16, 2020.
4. Parker WF, Churpek MM, Anderson AS. Is it too early to investigate survival outcomes of the new US heart allocation system? J Heart Lung Transplant. 2020;39:726.

5. Davies RR, Goff RR, Lease ED, Daly RC, Hall S. Commentary in reply to Cogswell et al.: an early investigation of outcomes with the new 2018 donor heart allocation system in the United States. J Heart Lung Transplant. 2020;39:726-8.

6. Yin MY, Wever-Pinzon O, Mehra MR, Selzman CH, Toll AE, Cherikh WS, et al. Post-transplant outcome in patients bridged to transplant with temporary mechanical circulatory support devices. J Heart Lung Transplant. 2019;38:858-69.

7. Agence de la Biomédecine: 2016 Annual Report of the "Agence de laBiomédecine"; 2016. Available at: https://www.agence-biomedecine.fr/annexes/ bilan2016/donnees/organes/03-coeur/synthese.htm. Accessed November 15, 2018.

8. Jasseron C, Lebreton G, Cantrelle C, Legeai C, Leprince P, Flecher E, et al. Impact of heart transplantation on survival in patients on venoarterial extracorporeal membrane oxygenation at listing in France. Transplantation. 2016;100: 1979-87.

9. Urban M, Siddique A, Merritt-Genore HM, Um J. What are the results of venoarterial extracorporeal membrane oxygenation bridging to heart transplantation? Interact Cardiovasc Thorac Surg. 2019;29:632-4.

10. Guha A, Hannawi B, Cruz-Solbes A, Nguyen DT, Bruckner BA, Trachtenberg B, et al. Implication of ventricular assist devices in extracorporeal membranous oxygenation patients listed for heart transplantation. J Clin Med. 2019;8:572.

11. Zalawadiya S, Fudim M, Bhat G, Cotts W, Lindenfeld J. Extracorporeal membrane oxygenation support and post-heart transplant outcomes among United States adults. J Heart Lung Transplant. 2017;36:77-81.

12. Rousse N, Juthier F, Pincon C, Hysi I, Banfi C, Robin E, et al. ECMO as a bridge to decision: recovery, VAD, or heart transplantation? Int J Cardiol. 2015;187:620-7.

13. Coutance G, Jacob N, Demondion P, Nguyen LS, Bouglé A, Bréchot N, et al. Favorable outcomes of a direct heart transplantation strategy in selected patients on extracorporeal membrane oxygenation support. Crit Care Med. 2020;48:498-506.

14. Guglin M, Zucker MJ, Bazan VM, Bozkurt B, Bozkurt B, El Banayosy A, et al. The present and future. Venoarterial ECMO for adults. JACC scientific expert panel. J Am Coll Cardiol. 2019;73:698-716.

15. Ouyang D, Gulati G, Ha R, Banerjee D. Incidence of temporary mechanical circulatory support before heart transplantation and impact on post-transplant outcomes. J Heart Lung Transplant. 2018;37:1060-6.

16. Nwaejike N, Son AY, Milano CA, Daneshmand MA. Is there a role for upperextremity intra-aortic balloon counterpulsation as a bridge-to-recovery or a bridge-to-transplant in the treatment of end-stage heart failure? Interact Cardiovasc Thorac Surg. 2017;25:654-8.

17. Estep JD, Cordero-Reyes AM, Bhimaraj A, Trachtenberg B, Khalil N, Loebe M, et al. Percutaneous placement of an intra-aortic balloon pump in the left axillary/ subclavian position provides safe, ambulatory long-term support as bridge to heart transplantation. JACC Heart Fail. 2013;1:382-8.

18. Houston Methodist DeBakey CV Education. Percutaneous Axillary IABP Placement (Jerry D. Estep, MD, FACC); May 10, 2018. Available at: https://www. youtube.com/watch? $\mathrm{v}=$ KemP5P1NVMQ. Accessed February 18, 2020.

19. Bhimaraj A, Agrawal T, Duran A, Tamimi O, Amione-Guerra J, Trachtenberg B, et al. Percutaneous left axillary artery placement of intra-aortic balloon pump in advanced heart failure patients. J Am Coll Cardiol. 2020;8:313-23.

20. Hall SA, Uriel N, Carey SA, Edens M, Gong G, Edens M, et al. Use of a percutaneous temporary circulatory support device as a bridge to decision during acute decompensation of advanced heart failure. J Heart Lung Transplant. 2018;37:100-6.

21. Mehra MR, Goldstein DJ, Uriel N, Cleveland JC Jr, Yuzefpolskaya M, Salerno C, et al. Two-year outcomes with a magnetically levitated cardiac pump in heart failure. N Engl J Med. 2018;378:1386-95.

22. Teuteberg JJ, Cleveland JC, Cowger J, Higgins RS, Goldstein DJ, Keebler M, et al. The Society of Thoracic Surgeons intermacs 2019 annual report: the changing landscape of devices and indications. Ann Thorac Surg. 2020;109:649-60.

23. Chambers DC, Cherikh WS, Harhay MO, Hayes D Jr, Hsich E, Khush KK, et al. The international thoracic organ transplant registry of the International Society for Heart and Lung Transplantation: thirty-sixth adult heart transplantation report-2019; focus theme: donor and recipient size match. J Heart Lung Transplant. 2019;38:1042-55.

Key Words: heart transplantation, donor allocation system, temporary mechanical circulatory support, extracorporeal membrane oxygenation, intra-aortic balloon pump, Impella 